\title{
High-sensitivity C-reactive protein to detect metabolic syndrome in a centrally obese population: a cross-sectional analysis
}

\author{
Corine den Engelsen ${ }^{1 *}$, Paula S Koekkoek', Kees J Gorter ${ }^{1}$, Maureen van den Donk', Philippe L Salomé ${ }^{2}$ and \\ Guy E Rutten ${ }^{1}$
}

\begin{abstract}
Background: People with central obesity have an increased risk for developing the metabolic syndrome, type 2 diabetes and cardiovascular disease. However, a substantial part of obese individuals have no other cardiovascular risk factors, besides their obesity. High sensitivity C-reactive protein (hs-CRP), a marker of systemic inflammation and a predictor of type 2 diabetes and cardiovascular disease, is associated with the metabolic syndrome and its separate components. We evaluated the use of hs-CRP to discriminate between centrally obese people with and without the metabolic syndrome.
\end{abstract}

Methods: 1165 people with central obesity but without any previous diagnosis of hypertension, dyslipidemia, diabetes or cardiovascular disease, aged 20-70 years, underwent a physical examination and laboratory assays to determine the presence of the metabolic syndrome (NCEP ATP III criteria). Multivariable linear regression analyses were performed to assess which metabolic syndrome components were independently associated with hs-CRP. A ROC curve was drawn and the area under the curve was calculated to evaluate whether hs-CRP was capable to predict the presence of the metabolic syndrome.

Results: Median hs-CRP levels were significantly higher in individuals with central obesity with the metabolic syndrome ( $n=417 ; 35.8 \%$ ) compared to individuals with central obesity without the metabolic syndrome ( $2.2 \mathrm{mg} /$ L (IQR 1.2-4.0) versus $1.7 \mathrm{mg} / \mathrm{L}$ (IQR 1.0-3.4); $p<0.001$ ). Median hs-CRP levels increased with an increasing number of metabolic syndrome components present. In multivariable linear regression analyses, waist circumference and triglycerides were the only components that were independently associated with hs-CRP after adjusting for smoking, gender, alcohol consumption and the other metabolic syndrome components. The area under the ROC curve was 0.57 (95\%-Cl 0.53-0.60).

Conclusions: Hs-CRP has limited capacity to predict the presence of the metabolic syndrome in a population with central obesity.

Keywords: Abdominal obesity, Metabolic syndrome, Screening, High-sensitivity C-reactive protein

\section{Background}

The metabolic syndrome (MetS) is a cluster of cardiovascular risk factors associated with an increased risk for developing cardiovascular disease and type 2 diabetes [1]. In recent years systemic inflammation - which can be measured by high sensitivity C-reactive protein (hs-CRP)

\footnotetext{
* Correspondence: c.denengelsen-2@umcutrecht.nl

'Julius Center for Health Sciences and Primary Care, University Medical

Center Utrecht, Utrecht, The Netherlands

Full list of author information is available at the end of the article
}

- has become an important marker for cardiovascular disease and type 2 diabetes [2-4]. Moreover hs-CRP is associated with the MetS and its separate components. Early diagnosis of the MetS is desirable as lifestyle interventions and adequate treatment of risk factors associated with the MetS can prevent cardiovascular disease $[5,6]$. However, it is not clear whether hs-CRP can also predict the presence of the MetS. Previous research showed that measuring an increased waist circumference was a reliable first step in detecting individuals with the MetS and 
was easy to perform [7]. However, a substantial part of the individuals with central obesity have no other cardiovascular risk factors [8,9]. Further assessment of risk for cardiovascular disease, after initial (self-)measurement of waist circumference, involves physical examination and laboratory assays. An elevated hs-CRP could be used to further distinguish those with the MetS from those without and diminish the group qualifying for further examinations. Therefore the aim of this study was to evaluate the use of hs-CRP to discriminate those with the MetS from those without the MetS in a population with central obesity.

\section{Methods}

\section{Study design and participants}

A cross-sectional screening study was performed in five primary health care centres in IJsselstein, a small city in the centre of the Netherlands. The aim was to determine the feasibility of screening for the MetS by measuring waist circumference as a first step and to assess the prevalence of the MetS [7]. Almost 12000 individuals received a tape measure to determine their own waist circumference. They were 20 to 70 years old and had no previous diagnosis of cardiovascular disease, diabetes, hypertension or dyslipidemia, nor did they use medication for any of these conditions. Individuals with an increased self-measured waist circumference $(\geq 88 \mathrm{~cm}$ in women; $\geq 102 \mathrm{~cm}$ in men) were invited for further examinations. Between September 2006 and May 2007, 1721 individuals with an increased self-measured waist circumference underwent all study procedures. Only participants with actual central obesity (a waist circumference $\geq 88 \mathrm{~cm}$ in women and $\geq 102 \mathrm{~cm}$ in men, measured by the investigators) were included in the present analyses.

The study was approved by the medical ethics committee of the University Medical Center Utrecht, the Netherlands. Written informed consent was obtained from all participants.

\section{Measurements}

In a physical examination body weight, height, waist circumference and blood pressure were measured. Examinations were described in detail previously [7]. Venous blood samples were drawn after an overnight fast to determine fasting blood glucose, lipids (triglycerides, total cholesterol, LDL cholesterol and HDL cholesterol) and hs-CRP. LDL cholesterol was calculated using the Friedewald formula. Hs-CRP was analysed by latex-enhanced turbidimetric assay (Cobas Integra 800 Analyzer, Roche Diagnostics).

The participants completed a questionnaire to determine ethnicity, lifestyle factors (smoking habits, alcohol use, and physical activity), relevant medical history, socioeconomic and demographic variables. Physical activity was assessed using the validated SQUASH questionnaire [10], which measures habitual activities with respect to occupation, leisure time, household tasks, transportation means, and other daily activities. The results were dichotomised based on the Dutch Standard Healthy Movement: a minimum of thirty minutes of exercise at least five days a week [11]. The use of alcohol was divided into three categories: no alcohol consumption, moderate alcohol consumption (one to 14 units per week for women, one to 21 units per week for men) and excessive alcohol consumption (more than 14 units per week for women, more than 21 units per week for men). Smoking was regarded positive when the participant was currently smoking tobacco; in case of former or never smoking it was regarded negative.

Participants were informed about the results of physical and laboratory examinations and in case of detected cardiovascular risk factors they received usual care by their general practitioner [12].

\section{Outcome measure}

The presence of the MetS was defined by the criteria of the NCEP ATP III [13]. The diagnosis was made when at least three of the five following criteria were present: waist circumference $\geq 88 \mathrm{~cm}$ (women) or $\geq 102 \mathrm{~cm}$ (men); triglycerides $\geq 1.7 \mathrm{mmol} / \mathrm{L}$; HDL cholesterol $<1.3$ $\mathrm{mmol} / \mathrm{L}$ (women) or $<1.0 \mathrm{mmol} / \mathrm{L}$ (men); blood pressure $\geq 130 / \geq 85 \mathrm{mmHg}$; fasting glucose $\geq 6.1 \mathrm{mmol} / \mathrm{L}$.

\section{Data analyses}

All statistical analyses were performed with SPSS, version 15.0 (SPSS, Chigaco, Illinois). Categorical variables are reported as numbers and percentages, continuous variables as means with standard deviations (SD) and non normally distributed variables as median with interquartile range (IQR). Differences between groups were analysed with Chisquare tests for categorical variables, independent $t$-tests for normally distributed continuous variables and MannWhitney tests for non normally distributed continuous variables. Hs-CRP was divided into three categories based on the cut-off points for risk stratification for cardiovascular risk [14]. A level below $1.0 \mathrm{mg} / \mathrm{L}$ is considered a low cardiovascular risk, between 1.0 and $3.0 \mathrm{mg} / \mathrm{L}$ an intermediate risk and between 3.0 and $10.0 \mathrm{mg} / \mathrm{L}$ a high risk. A level above $10.0 \mathrm{mg} / \mathrm{L}$ is associated with active infection and therefore not applicable in the risk estimation [15]. Individuals with an hs-CRP level above $10.0 \mathrm{mg} / \mathrm{L}$ were excluded from the analyses.

Univariable linear regression analyses were used to calculate the $\mathrm{p}$ for trend over hs-CRP categories, in which the hs-CRP categories were used as independent variable. A multivariable linear regression analysis was performed to assess which MetS components were independently associated with hs-CRP. In this analysis hs-CRP and triglycerides were logtransformed because of their skewed distribution. Waist circumference and HDL cholesterol 
were also transformed, taking into account the gender specific thresholds. The gender specific threshold was extracted from the values obtained in the examinations. The new variables indicate the absolute difference with the gender specific threshold. A ROC curve was drawn and the area under the curve was calculated to evaluate whether hs-CRP is capable to predict the presence of the MetS. Sensitivity, specificity and the positive and negative predictive values for different hs-CRP cut-off points were calculated.

\section{Results}

Of the 1721 participants with a self-measured increased waist-circumference that completed all study procedures 108 individuals were excluded from the analyses because of an hs-CRP above $10.0 \mathrm{mg} / \mathrm{L} .1165$ individuals had an actual increased waist circumference, measured by the investigator. The mean age in the participants with an actual increased waist circumference was 48.4 (SD 10.7) years, $92.7 \%$ were Caucasian and $65.2 \%$ were female. The prevalence of MetS in this population with central obesity was $35.8 \%(n=417)$. Table 1 shows the patient characteristics for the individuals with an increased waist circumference with and without the MetS. The median hs-CRP for the total population was $1.9 \mathrm{mg} / \mathrm{L}$ (IQR 1.1-
3.6). In the population with the MetS the median hs-CRP was $2.2 \mathrm{mg} / \mathrm{L}$ (IQR 1.2-4.0), compared to $1.7 \mathrm{mg} / \mathrm{L}$ (IQR $1.0-3.4)$ in the group without the MetS $(p<0.001)$.

With an increasing number of MetS components present, median hs-CRP increased from $1.5 \mathrm{mg} / \mathrm{L}$ (IQR 0.9-2.9) to 1.9 (IQR 1.1-3.5), 2.1 (IQR 1.1-4.0), 2.4 (IQR 1.5-4.5) and $2.2 \mathrm{mg} / \mathrm{L}$ (IQR 1.4-4.4) in the groups with respectively one $(\mathrm{n}=234)$, two $(\mathrm{n}=514)$, three $(\mathrm{n}=$ $301)$, four $(\mathrm{n}=103)$ and five $(\mathrm{n}=13)$ components ( $p$ for trend $<0.001$ ).

Table 2 shows the clinical and biochemical characteristics according to hs-CRP categories. A significant linear trend over increasing hs-CRP categories was seen for the presence of the MetS and for three of its components: waist circumference, triglycerides and HDL cholesterol. BMI, gender, current tobacco smoking and current alcohol consumption also showed a significant linear trend. In a multivariable linear regression analysis, waist circumference and triglycerides were the only MetS components that were independently associated with hs-CRP, after adjusting for smoking, gender, alcohol consumption and the other MetS components (Table 3).

The area under the ROC curve for hs-CRP was 0.57 (95\%-CI 0.53-0.60) (Figure 1).

Table 1 Patient characteristics for the total population and according to the presence of the metabolic syndrome

\begin{tabular}{|c|c|c|c|c|}
\hline Characteristics & Total $n=1165$ & Metabolic syndrome present $n=417$ & Metabolic syndrome absent $n=748$ & P-value \\
\hline Age (years) & $48.4 \pm 10.7$ & $48.5 \pm 10.5$ & $48.3 \pm 10.8$ & 0.76 \\
\hline Gender (\%, female) & 65.2 & 48.0 & 74.9 & $<0.001$ \\
\hline \multicolumn{5}{|l|}{ Waist circumference $(\mathrm{cm})$} \\
\hline - Female & $97.7 \pm 8.1$ & $100.3 \pm 9.2$ & $96.7 \pm 7.4$ & $<0.001$ \\
\hline - Male & $109.7 \pm 6.6$ & $110.5 \pm 6.9$ & $108.9 \pm 6.3$ & 0.01 \\
\hline $\mathrm{BMI}\left(\mathrm{kg} / \mathrm{m}^{2}\right)$ & $29.5 \pm 3.6$ & $30.3 \pm 3.6$ & $29.1 \pm 3.5$ & $<0.001$ \\
\hline \multicolumn{5}{|l|}{ Blood pressure (mmHg) } \\
\hline - Systolic & $137.7 \pm 17.3$ & $144.8 \pm 15.8$ & $133.7 \pm 16.8$ & $<0.001$ \\
\hline - Diastolic & $84.8 \pm 9.3$ & $88.7 \pm 7.9$ & $82.7 \pm 9.3$ & $<0.001$ \\
\hline Triglycerides (mmol/L) & $1.2(0.9-1.8)$ & $1.9(1.7-2.4)$ & $1.0(0.8-1.3)$ & $<0.001$ \\
\hline \multicolumn{5}{|l|}{ HDL cholesterol (mmol/L) } \\
\hline - Female & $1.6 \pm 0.4$ & $1.3 \pm 0.3$ & $1.7 \pm 0.4$ & $<0.001$ \\
\hline - Male & $1.2 \pm 0.3$ & $1.1 \pm 0.3$ & $1.4 \pm 0.2$ & $<0.001$ \\
\hline LDL cholesterol (mmol/L) & $3.2 \pm 0.9$ & $3.4 \pm 0.9$ & $3.2 \pm 0.8$ & $<0.001$ \\
\hline Fasting glucose (mmol/L) & $5.0 \pm 0.9$ & $5.4 \pm 1.4$ & $4.9 \pm 0.5$ & $<0.001$ \\
\hline $\mathrm{Hs}-\mathrm{CRP}(\mathrm{mg} / \mathrm{L})$ & $1.9(1.1-3.6)$ & $2.2(1.2-4.0)$ & $1.7(1.0-3.4)$ & $<0.001$ \\
\hline Physical activity meeting Dutch & 59.5 & 56.1 & 61.3 & 0.09 \\
\hline \multicolumn{5}{|l|}{ Standard Healthy Movement ${ }^{\ddagger}(\%)$} \\
\hline Current smoking (\%) & 20.3 & 24.6 & 17.9 & 0.01 \\
\hline Alcohol consumption (\%) & & & & 0.03 \\
\hline - None & 28.3 & 31.1 & 26.7 & \\
\hline - Moderate & 64.5 & 59.8 & 67.1 & \\
\hline - Excessive & 7.2 & 9.2 & 6.2 & \\
\hline
\end{tabular}

Data are reported as means \pm standard deviation or percentage. Non normally distributed variables are reported as median (25th-75th percentile).

" Dutch Standard Healthy Movement: a minimum of thirty minutes of exercise at least five days a week. 
Table 2 Patient characteristics across hs-CRP cardiovascular risk level categories

\begin{tabular}{|c|c|c|c|c|}
\hline & $\mathrm{hs}-\mathrm{CRP}$ (mg/L) & & & $P$ for trend \\
\hline & $<1.0 n=254$ & $\geq 1.0-\leq 3.0 n=545$ & $>3.0-<10.0 n=366$ & \\
\hline Age (years) & $47.9 \pm 10.6$ & $49.6 \pm 10.6$ & $47.0 \pm 10.7$ & 0.15 \\
\hline Gender (\%, female) & 61.0 & 61.5 & 73.8 & $<0.001$ \\
\hline Waist circumference $(\mathrm{cm})$ & & & & \\
\hline - Female & $95.0 \pm 5.5$ & $96.8 \pm 7.6$ & $100.3 \pm 9.0$ & $<0.001$ \\
\hline - Male & $106.9 \pm 3.4$ & $110.0 \pm 6.2$ & $112.1 \pm 8.6$ & $<0.001$ \\
\hline Triglycerides (mmol/L) & $1.1(0.8-1.6)$ & $1.2(0.9-1.8)$ & $1.3(0.9-1.8)$ & $<0.01$ \\
\hline LDL cholesterol (mmol/L) & $3.2 \pm 0.9$ & $3.2 \pm 0.8$ & $3.2 \pm 0.9$ & 0.78 \\
\hline HDL cholesterol (mmol/L) & & & & \\
\hline - Female & $1.7 \pm 0.4$ & $1.6 \pm 0.4$ & $1.5 \pm 0.4$ & $<0.001$ \\
\hline - Male & $1.3 \pm 0.3$ & $1.2 \pm 0.3$ & $1.2 \pm 0.3$ & 0.02 \\
\hline Blood pressure (mmHg) & & & & \\
\hline - Systolic & $135.7 \pm 15.4$ & $138.2 \pm 17.5$ & $138.3 \pm 18.1$ & 0.09 \\
\hline - Diastolic & $84.2 \pm 8.5$ & $84.8 \pm 9.3$ & $85.3 \pm 9.8$ & 0.12 \\
\hline Fasting glucose (mmol/L) & $5.0 \pm 0.7$ & $5.0 \pm 1.0$ & $5.1 \pm 1.0$ & 0.10 \\
\hline $\mathrm{BMI}\left(\mathrm{kg} / \mathrm{m}^{2}\right)$ & $28.3 \pm 3.0$ & $29.4 \pm 3.2$ & $30.6 \pm 4.2$ & $<0.001$ \\
\hline Metabolic syndrome (\%) & 29.5 & 34.7 & 41.8 & $<0.01$ \\
\hline Current smoking (\%) & 19.3 & 17.6 & 25.0 & 0.05 \\
\hline Drinking alcohol (\%) & & & & $<0.01$ \\
\hline - None & 20.9 & 27.9 & 34.0 & \\
\hline - Moderate & 70.5 & 64.9 & 59.7 & \\
\hline - Excessive & 8.7 & 7.2 & 6.3 & \\
\hline Physical activity meeting Dutch Standard Healthy Movement ${ }^{\ddagger}(\%)$ & 55.5 & 61.3 & 59.5 & 0.41 \\
\hline
\end{tabular}

Data are reported as means \pm standard deviation or percentage. Non normally distributed variables are reported as median (25th-75th percentile).

‡ Dutch Standard Healthy Movement: a minimum of thirty minutes of exercise at least five days a week.

At a cut-off point for hs-CRP at a level of $1.0 \mathrm{mg} / \mathrm{L}$ the sensitivity and specificity of hs-CRP for the MetS were $82 \%$ and $24 \%$, respectively. The positive and negative predictive values for this level were $38 \%$ and $71 \%$ respectively. At a cut-off level of $3.0 \mathrm{mg} / \mathrm{L}$ the sensitivity and specificity were $37 \%$ and $72 \%$ respectively. The positive and negative predictive values for this level were $42 \%$ and $67 \%$ respectively.

\section{Discussion}

Median hs-CRP levels were significantly higher in individuals with central obesity with the MetS compared to

Table 3 Associations between metabolic syndrome components and hs-CRP in multivariable linear regression analysis

\begin{tabular}{llll}
\hline & B & $\mathbf{( 9 5 \% - C l )}$ & P-value \\
\hline Waist circumference $(\mathrm{cm})$ & 0.03 & $(0.02 ; 0.03)$ & $<0.001$ \\
Triglycerides $(\mathrm{mmol} / \mathrm{L})$ & 0.21 & $(0.10 ; 0.32)$ & $<0.001$ \\
HDL cholesterol $(\mathrm{mmol} / \mathrm{L})$ & -0.06 & $(-0.20 ; 0.09)$ & 0.43 \\
Systolic blood pressure $(\mathrm{mmHg})$ & 0.00 & $(-0.00 ; 0.01)$ & 0.11 \\
Fasting glucose $(\mathrm{mmol} / \mathrm{L})$ & -0.02 & $(-0.08 ; 0.03)$ & 0.37 \\
\hline
\end{tabular}

$\mathrm{B}$, unstandardized regression coefficient, adjusted for gender, smoking status, alcohol consumption and the other metabolic syndrome components. Cl, confidence interval.

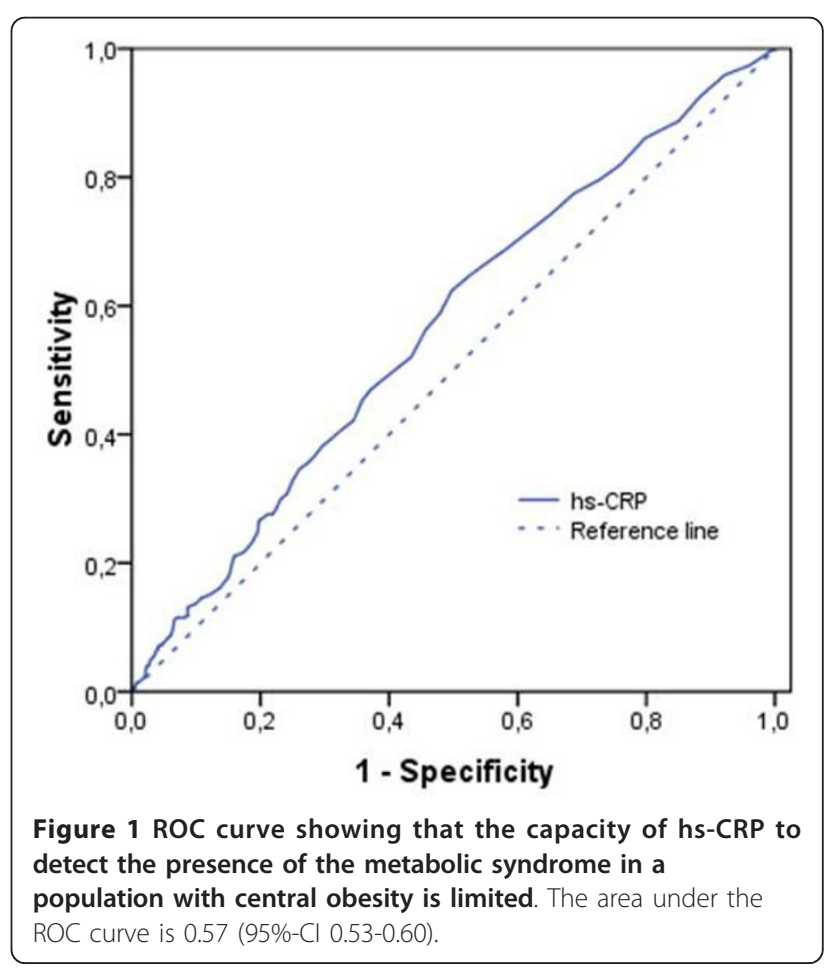


individuals with central obesity without the MetS. Median hs-CRP levels increased with an increasing number of MetS components present. The presence of the MetS, waist circumference, triglycerides and HDL cholesterol showed a significant trend over increasing hs-CRP categories. However the area under the ROC curve was 0.57, indicating that hs-CRP cannot predict the presence of the MetS in a population with central obesity.

Strengths of this study were the large number of people and the wide variety in age, also including younger people. Our study population consisted of individuals without known cardiovascular disease, diabetes, hypertension or dyslipidemia; besides an increased waist circumference they were considered healthy. However because of their increased waist circumference they were at risk for developing cardiovascular disease and were therefore a relevant population for studying the use of hs-CRP as a screening tool for early detection of the MetS.

A limitation of this study was the cross-sectional design. We only performed measurements at one time point. HsCRP is a sensitive marker for acute phase inflammation and has a high within-subject variability [16]. A value above five might indicate an increased cardiovascular risk, but could also be an hs-CRP returning to normal low levels after an infection [14]. However, since we intended to explore the predictive value of hs-CRP measured at one time point for detecting the presence of the MetS, our design reflects routine in daily practice.

We found hs-CRP levels to be higher in centrally obese individuals with the MetS, compared to those without. This is in line with several studies which found higher hs-CRP levels in individuals with the MetS, both in obese and non-obese populations and in Caucasian and nonCaucasian populations [17-25]. Also a linear increase in hs-CRP levels with an increasing number of components of the MetS was described previously [18-21,23,25-27]. Over increasing hs-CRP risk level categories the percentage of people with the MetS increased significantly. A similar significant trend was found for mean waist circumference and HDL cholesterol and median triglyceride levels. But only waist circumference and triglycerides showed a significant independent association with hsCRP in multivariable analysis. Several studies have assessed the relation between hs-CRP and different MetS components. In univariable analyses most of them showed significant associations for the individual MetS components. Studies that also assessed multivariable associations, thereby adjusting for other MetS components, mostly report that central obesity was the major determinant of elevated hs-CRP levels in individuals with the MetS. The other MetS components do not, or only marginally, increase hs-CRP level [17-20,26,28]. This might explain why hs-CRP cannot be used to predict the presence of the MetS in our study, indicated by an area under the ROC curve of 0.57 .

The relationship between central obesity and increased levels of hs-CRP has been well studied. Adipose tissue is known to secrete cytokines that stimulate the production of hs-CRP in the liver, but adipose tissue itself may also secrete hs-CRP and thereby raise hs-CRP levels [29]. Genetic polymorphisms could partially explain the inter-individual variability observed in the inflammatory profile of obese patients and the inter-individual variability in metabolic perturbations associated with obesity [30,31].

Although central obesity seems to be the major determinant of elevated hs-CRP levels in the MetS, significant independent associations between hs-CRP and other components were found. As in our study, Aronson et al. found an independent association between triglyceride level and hs-CRP. In addition they found associations between hs-CRP and glucose level and HDL cholesterol. However, this only accounted for $\sim 1 \%$ of the variability in CRP levels [26].

Two other studies also found an independent association between hs-CRP and fasting glucose [21,32]. We did not find such an association, which might be due to the limited number of individuals with a high glucose level $(\geq 6.1 \mathrm{mmol} / \mathrm{L})$ in our study population $(\mathrm{n}=66$; $5.7 \%)$. General practitioners in the Netherlands are alert in screening for diabetes as a result of which the number of patients with undiagnosed diabetes is limited [33].

\section{Conclusions}

In our population with central obesity, measurement of hs-CRP cannot be used to further discriminate MetS status. The degree of central obesity seemed to be the main determinant of an increased hs-CRP level; the association with other MetS components was not strong enough to enable further discrimination. While hs-CRP does not distinguish metabolic syndrome well on its own, it may have utility in conjunction with other tests, which requires further testing. In addition, hs-CRP could still be used as a prognostic marker of cardiovascular disease and diabetes. This would enable physicians to determine which centrally obese individuals should be encouraged most strongly to adapt a healthier lifestyle.

\section{Abbreviations}

Hs-CRP: High-sensitivity C-reactive protein; MetS: Metabolic syndrome

\section{Acknowledgements}

The IJsselstein Study of Central Obesity to detect metabolic syndrome was supported in part by a research grant from the Investigator Initiated Studies Program of Merck Sharp \& Dome Corp (MSD). MSD had no role in the study design and conduct, the writing of the manuscript or the decision to submit the paper for publication. The opinions expressed in this presentation are those of the authors and do not necessarily represent those of MSD. 


\section{Author details}

'Julius Center for Health Sciences and Primary Care, University Medical Center Utrecht, Utrecht, The Netherlands. ' ${ }^{2}$ Huisartsenzorg IJsselstein, Locatie't Steyn, IJsselstein, The Netherlands.

\section{Authors' contributions}

CdE and PSK researched the data, performed the statistical analyses and wrote the manuscript. KJG, MvdD, PLS and GER contributed to the discussion. All authors were involved in the design of the study and read and approved the final manuscript.

\section{Competing interests}

The authors declare that they have no competing interests.

Received: 3 January 2012 Accepted: 14 March 2012

Published: 14 March 2012

\section{References}

1. Sattar N, McConnachie A, Shaper AG, Blauw GJ, Buckley BM, de Craen AJ, Ford I, Forouhi NG, Freeman DJ, Jukema JW, Lennon L, Macfarlane PW, Murphy MB, Packard CJ, Stott DJ, Westendorp RG, Whincup PH, Shepherd J, Wannamethee SG: Can metabolic syndrome usefully predict cardiovascular disease and diabetes? Outcome data from two prospective studies. Lancet 2008, 371:1927-1935.

2. Freeman DJ, Norrie J, Caslake MJ, Gaw A, Ford I, Lowe GD, O'Reilly DS, Packard CJ, Sattar N: C-reactive protein is an independent predictor of risk for the development of diabetes in the West of Scotland Coronary Prevention Study. Diabetes 2002, 51:1596-1600.

3. Ridker PM, Hennekens $\mathrm{CH}$, Buring JE, Rifai N: C-reactive protein and other markers of inflammation in the prediction of cardiovascular disease in women. N Engl J Med 2000, 342:836-843.

4. Ross R: Atherosclerosis is an inflammatory disease. Am Heart J 1999, 138 S419-S420.

5. Mlanne-Parikka P, Eriksson JG, Lindstrom J, Peltonen M, Aunola S, Hamalainen $\mathrm{H}$, Keinanen-Kiukaanniemi S, Laakso M, Valle TT, Lahtela J, Uusitupa M, Tuomilehto J: Effect of lifestyle intervention on the occurrence of metabolic syndrome and its components in the Finnish Diabetes Prevention Study. Diabetes Care 2008, 31:805-807.

6. Wong ND, Pio JR, Franklin SS, L'Italien GJ, Kamath TV, Williams GR: Preventing coronary events by optimal control of blood pressure and lipids in patients with the metabolic syndrome. Am J Cardiol 2003, 91:1421-1426.

7. Van den Donk M, Bobbink IWG, Gorter KJ, Salomé PL, Rutten GEHM: Identifying people with metabolic syndrome in primary care by screening with a mailed tape measure. A survey of 14,000 people in the Netherlands. Prev Med 2009, 48:345-350.

8. Pataky Z, Bobbioni-Harsch E, Golay A: Open questions about metabolically normal obesity. Int J Obes (Lond) 2010, 34(Suppl 2):S18-S23.

9. Wildman RP, Muntner P, Reynolds K, McGinn AP, Rajpathak S, WylieRosett J, Sowers MR: The obese without cardiometabolic risk factor clustering and the normal weight with cardiometabolic risk factor clustering: prevalence and correlates of 2 phenotypes among the US population (NHANES 1999-2004). Arch Intern Med 2008, 168:1617-1624.

10. Wendel-Vos GC, Schuit AJ, Saris WH, Kromhout D: Reproducibility and relative validity of the short questionnaire to assess health-enhancing physical activity. J Clin Epidemiol 2003, 56:1163-1169.

11. Kemper HGC, Ooijendijk WTM, Stiggelbout M: Consensus over de Nederlandse Norm voor Gezond Bewegen. Tijdschrift voor Sociale Gezondheidszorg 2000, 78:180-183.

12. Stalman WA, Scheltens T, Burgers JS, Hukkelhoven CW, Smorenburg SM, Banga JD, Dippel DW: NHG-Standaard Cardiovasculair risicomanagement Houten: Bohn Stafleu van Loghum; 2006.

13. Alberti KG, Eckel RH, Grundy SM, Zimmet PZ, Cleeman JI, Donato KA, Fruchart JC, James WP, Loria CM, Smith SC Jr: Harmonizing the metabolic syndrome: a joint interim statement of the International Diabetes Federation Task Force on Epidemiology and Prevention; National Heart, Lung, and Blood Institute; American Heart Association; World Heart Federation; International Atherosclerosis Society; and International Association for the Study of Obesity. Circulation 2009, 120:1640-1645.

14. Taubert K, Tracy RP, Vinicor F, Pearson TA, Mensah GA, Alexander RW, Anderson JL, Cannon RO III, Criqui M, Fadl YY, Fortmann SP, Hong Y,
Myers GL, Rifai N, Smith SC Jr: Markers of inflammation and cardiovascular disease: application to clinical and public health practice: A statement for healthcare professionals from the Centers for Disease Control and Prevention and the American Heart Association. Circulation 2003, 107:499-511.

15. Morley JJ, Kushner I: Serum C-reactive protein levels in disease. Ann N Y Acad Sci 1982, 389:406-418.

16. Macy EM, Hayes TE, Tracy RP: Variability in the measurement of C-reactive protein in healthy subjects: implications for reference intervals and epidemiological applications. Clin Chem 1997, 43:52-58.

17. Dupuy AM, Jaussent I, Lacroux A, Durant R, Cristol JP, Delcourt C: Waist circumference adds to the variance in plasma C-reactive protein levels in elderly patients with metabolic syndrome. Gerontology 2007, 53:329-339.

18. Santos AC, Lopes C, Guimaraes JT, Barros H: Central obesity as a major determinant of increased high-sensitivity C-reactive protein in metabolic syndrome. Int J Obes (Lond) 2005, 29:1452-1456.

19. Zuliani G, Volpato S, Galvani M, Ble A, Bandinelli S, Corsi AM, Lauretani F, Maggio M, Guralnik JM, Fellin R, Ferrucci L: Elevated C-reactive protein levels and metabolic syndrome in the elderly: The role of central obesity data from the InChianti study. Atherosclerosis 2009, 203:626-632.

20. Florez H, Castillo-Florez S, Mendez A, Casanova-Romero P, LarrealUrdaneta C, Lee D, Goldberg R: C-reactive protein is elevated in obese patients with the metabolic syndrome. Diabetes Res Clin Pract 2006, 71:92-100.

21. Gonzalez AS, Guerrero DB, Soto MB, Diaz SP, Martinez-Olmos M, Vidal O: Metabolic syndrome, insulin resistance and the inflammation markers Creactive protein and ferritin. Eur J Clin Nutr 2006, 60:802-809.

22. Kressel G, Trunz B, Bub A, Hulsmann O, Wolters M, Lichtinghagen R, Stichtenoth DO, Hahn A: Systemic and vascular markers of inflammation in relation to metabolic syndrome and insulin resistance in adults with elevated atherosclerosis risk. Atherosclerosis 2009, 202:263-271.

23. Lee WY, Park JS, Noh SY, Rhee EJ, Sung KC, Kim BS, Kang JH, Kim SW, Lee $M H$, Park JR: C-reactive protein concentrations are related to insulin resistance and metabolic syndrome as defined by the ATP III report. Int J Cardiol 2004, 97:101-106.

24. Kawamoto R, Tabara Y, Kohara K, Miki T, Kusunoki T, Takayama S, Abe M, Katoh T, Ohtsuka N: High-sensitivity C-reactive protein and gammaglutamyl transferase levels are synergistically associated with metabolic syndrome in community-dwelling persons. Cardiovasc Diabetol 2010, 9:87.

25. Mahajan A, Jaiswal A, Tabassum R, Podder A, Ghosh S, Madhu SV, Mathur SK, Tandon N, Bharadwaj D: Elevated levels of C-reactive protein as a risk factor for Metabolic Syndrome in Indians. Atherosclerosis 2012, 220:275-281.

26. Aronson D, Bartha P, Zinder O, Kerner A, Markiewicz W, Avizohar O, Brook GJ, Levy Y: Obesity is the major determinant of elevated C-reactive protein in subjects with the metabolic syndrome. Int J Obes Relat Metab Disord 2004, 28:674-679.

27. Frohlich M, Imhof A, Berg G, Hutchinson WL, Pepys MB, Boeing H, Muche R, Brenner $H$, Koenig W: Association between C-reactive protein and features of the metabolic syndrome: a population-based study. Diabetes Care 2000, 23:1835-1839.

28. Lu B, Yang Y, Yang Z, Feng $X$, Wang $X$, Zhang $Z$, Hu R: Insulin resistance in Chinese patients with type 2 diabetes is associated with C-reactive protein independent of abdominal obesity. Cardiovasc Diabetol 2010, 9:92.

29. Ouchi N, Kihara S, Funahashi T, Nakamura T, Nishida M, Kumada M, Okamoto Y, Ohashi K, Nagaretani H, Kishida K, Nishizawa H, Maeda N, Kobayashi H, Hiraoka H, Matsuzawa Y: Reciprocal association of C-reactive protein with adiponectin in blood stream and adipose tissue. Circulation 2003, 107:671-674.

30. Bouchard L, Tchernof A, Deshaies Y, Marceau S, Lescelleur O, Biron S, Vohl MC: ZFP36: a promising candidate gene for obesity-related metabolic complications identified by converging genomics. Obes Surg 2007, 17:372-382.

31. Faucher G, Guenard F, Bouchard L, Garneau V, Turcot V, Houde A Tchernof A, Bergeron J, Deshaies Y, Hould FS, Lebel S, Marceau P, Vohl MC: Genetic contribution to C-reactive protein levels in severe obesity. Mol Genet Metab 2011.

32. Niehoff AG, van Haeften TW, Onland-Moret NC, Elbers CC, Wijmenga C, van der Schouw YT: C-reactive protein is independently associated with 
glucose but not with insulin resistance in healthy men. Diabetes Care 2007, 30:1627-1629.

33. Janssen PG, Gorter KJ, Stolk RP, Rutten GE: Low yield of population-based screening for Type 2 diabetes in the Netherlands: the ADDITION Netherlands study. Fam Pract 2007, 24:555-561.

doi:10.1186/1475-2840-11-25

Cite this article as: den Engelsen et al:: High-sensitivity C-reactive

protein to detect metabolic syndrome in a centrally obese population:

a cross-sectional analysis. Cardiovascular Diabetology 2012 11:25.

Submit your next manuscript to BioMed Central and take full advantage of:

- Convenient online submission

- Thorough peer review

- No space constraints or color figure charges

- Immediate publication on acceptance

- Inclusion in PubMed, CAS, Scopus and Google Scholar

- Research which is freely available for redistribution

Submit your manuscript at www.biomedcentral.com/submit 